\title{
Opening the Curriculum through Open Educational Practices: International experience
}

\author{
Laura Ritchie \\ University of Chichester (United Kingdom) \\ I.ritchie@chi.ac.uk
}

\begin{abstract}
A successful international learning initiative focusing on student agency began with a link facilitating OE-enhanced teaching between a UK university and a US high school class. It became an international trip organised and funded by five UK students and their teacher who travelled to California, teaching and performing music across formal and informal learning settings. The project is now a credit-bearing class, retaining the original initiative's openness within the university curriculum where final-year students collaborate with the teacher, self-organising to design and plan curricular details from travel logistics to musical interactions. Students engage in heutagogy, demonstrating the highest levels of autonomous, personal learning in this co-learning environment. Their assessment, a reflective journal, encourages engage with deeper learning processes. The original trip was documented as an eBook including 10,000 student-authored words telling their collaborative learning journey. The book was published without DRM an accessible model for other students and educators.
\end{abstract}

Keywords: Student-led; Collaboration; Co-learning; Curriculum development; Open curriculum; Open educational practice

\section{Introduction}

Institutional learning is seldom without constraints; teachers navigate timetables, content, criteria, and resources as they devise and deliver the best possible learning experiences for the students. The understanding of student learning has long since progressed from being about content and knowledge to focusing on student-centred experiences and processes (Kolb, 1984). Although much of the taught content in higher education is personalised to focus on a specialism or type of student, a further step is required to transform this into truly personal learning where students initiate, create, and control their learning (for an in-depth discussion of personalised vs. personal learning see Downes, 2017). As students take control of their learning they seek information from sources and people, and the resulting web of connected practices are not limited to face-to-face encounters. Technology enables fast and easy connections across distances and cultures, and it is possible to engage with a wider, global learning community. Including aspects of open learning in teaching benefit students and teacher, but there can be resistance to change and sometimes it is difficult to integrate these into university class teaching (Garrison \& Vaughan, 2008). Lehtomäki, Moate and Posti-Ahokas (2016) stress the importance of innovating to create opportunity and mainstreaming internationalisation within university curricula, as "higher education institutions are to prepare global citizens for the uncertain future, where people, work and all matters are more interconnected than ever before" (p. 2011).

This article presents the pedagogic principles behind this curriculum innovation, discussing the benefits and challenges to teachers and students. The original student-led initiative and its outcomes are described, and suggestions are presented to transfer it across a range of disciplines to future classes and projects. 


\section{Background}

The Psychology of Learning \& Teaching class that I teach in the Music Department at the University of Chichester, has always engaged in various open educational practices: there is no text book, students are encouraged to reach out to the wider musical and teaching community to both seek information and apply concepts discussed in class. In 2015 a series of opportunities to connect and work across disciplines and cultures resulted in a dramatic change to the pattern of teaching and learning, beginning with a connection with Righetti High School's English class' teacher David Preston, in California, to explore issues of communication, motivation, and general interpersonal interactions when learning music. The UK students collaborated as a class-group, teaching music over Skype developed various individual and small-group projects involving exchanging sound recordings, making video tutorials, and teaching one-to-one lessons to the high school students. These connected activities were extra to the coursework, and completely optional to students, however they provided an open source dimension to the learning and allowed students a direct application of the teaching and learning concepts in the class.

One month later the high school teacher in California extended an invitation to meet the students and see the fruition of these collaborations first-hand, in America. The lecturer extended an invitation to the university class, simply asking who would like to do this, and five students immediately said yes, they would like to take the collaboration further and meet face-to-face. The five worked with their lecturer to plan, organise, and raise funds for their trip to California three months later in May 2015. The trip was completely outside the curriculum and the degree, but the students were inspired to make it happen. The project became a dramatic extension of the previous virtual collaborations and was a completely student-led initiative. The gravitas of connection motivated them, and the commitment and results were more than impressive.

There was no resistance from the university as the trip was completely separate from the curriculum. This meant the group were free of traditional constraints that go with a credit-class, e.g. no assessment or outcome requirements. Their lecturer underwrote the trip and there were real pressures to repay her costs. Without the help of a template or handbook, only a timescale, they were challenged to be innovative. The students quickly developed organisational and planning skills, set goals and achieved real financial deadlines, and learned public speaking and blogging skills as they prepared and raised funds for the trip. This integration of skills and deliverables was far more demanding than components of any traditional curriculum, and because the students had chosen to undertake the project, they were that much more motivated, despite the daunting elements of purchasing plane tickets, organising car hire, and the unknown anticipation of meeting students in California. As one student from the group explained, "Failing wasn't an option for us. There was no plan B. When we said we are going to America, we were going" (Ritchie, 2017, p. 61). Over the following three months, the group raised $£ 8,000$ toward the trip, and further significant in-kind donations were received toward accommodation, board, and transportation needs to drive the group and their instruments over 700 miles from Los Angeles (LA) to Yosemite and back again.

\section{Open Curriculum}

This was the first project of this type these students had met in their education where there were no fixed outcomes beyond the experience itself. They knew they would meet the high school students and share music with them, and expected this sharing would involve some form of teaching and performance. They named the initiative Musiquality and their aim was 'to bring connection and quality through music' and specific goals were left open, to be quantified by the group; nearly all the surrounding details of learning, preparation, and delivery were left to them. There was no exam, 
or culminating single moment to define 'the trip'. The demands on their cognitive understanding required both a macro and microscopic analysis of events in real time, for the logistical planning alone. The musical preparation undertaken was more typical of previously learned tasks, but the radically different interpersonal dynamics of the group made this a steep learning curve.

The alignment of skills, aims, learning and future tasks, encourages an awareness of experience, and deeper learning. The value of the aims and outcomes is in the individual and collaborative experience, the reflections occurring during the days and months following the trip, and the resulting wider perspective. Articulating these applications through reflection, in this instance to capture the open nature of the experience, enabled student transitions out of learning and into life to have 'less abrasion' (Askham, 2008).

\section{Teacher / Student Roles}

Students and teacher become interdependent peers, each leading with one hand while supporting with the other. Learning happens through experience, as active, student-directed activity, and the outcomes of the preparatory experiences enable the group to form a networked built on people's strengths and supported their weaknesses. Without the constraints of the classroom or timed sessions, students can self-select and formed its learning through processes resembling an integration of children's experimentation when playing and the motion of a murmuration of birds. Downes (2017) describes this bird-cloud as a "perceptual system for starlings" (p. 358). Each bird is in tune to others around, and this adaptive, learned behaviour developed to best suit the birds and their situation.

The international and collaborative aspects of the trip put different responsibilities on students that impact learning beyond any closed classroom or textbook setting. To encourage the students to take on pedagogic responsibility, the lecturer put herself in the genuine position of a learner, taking on an unfamiliar musical role within the group, and the students assumed responsibility for teaching the 'teacher'. In this case the lecturer was taught to be a singer in a band, and relied on the expertise of the students to learn. As opposed to a modelled situation, when the learning is essentially an act, here the teacher-student roles were truly reversed. Professionally, many teachers would not be comfortable choosing this risk, as it required trust in the teaching and mentoring demonstrated by the students, openness in learning, and there was more than a chance of being exposing as a failure when the group performed together in America.

As in the work and experience of Horton and Freire (1990), when the learner is allowed to control the path of their education, so much more can be accomplished. Their international experience quickly became an immersive experience that exceeded any classroom-based role-play or simulated experience from the realm of a workshop, game, or practice, into reality. In America the group worked with a variety of students and teachers in both formal school settings and informal creative spaces, ranging from performing in a racquet ball court in UCLA, to recording a song with high school students in a lodge in Yosemite, to teaching kindergarteners singing and clapping games on the grass outside their classroom. The scope of the initiative and its success demonstrate the range of possibilities when students are enabled to lead learning without the implied boundaries of the classroom and formal education settings. The trip was not without teacher direction, but this type of learning requires a different type of teaching that is more "mentoring and guiding development" (de Freitas et al., 2010, p. 82). The theoretical framework underpinning this is based on a mixture of the pedagogical ideas found in heutagogy (Blaschke, 2012), experiential learning, co-learning (see The Peeragogy Handbook [Corneli et al., 2016], and Howard Rheingold's Stanford course Social Media Issues: http://socialmediaissues.net/), and connectivism (Siemens, 2005; Downes, 2017). 
These all involve taking active responsibility for self-directed, autonomous learning and aspects of connection, reaching out to other sources both within and outside the group.

As opposed to focusing the learning on individual tasks or specific content, there was a shift similar to that found in immersive game design, to "choreographing learning experiences as a whole, mediated by structured and semi-structured social interactions" (de Freitas et al., 2010, p. 82). From the skills come the tasks became the framework for a module attending to core concepts and skills, but build in a way that the tasks could be different every year, depending on and decided by the cohort.

\section{Integration into the curriculum}

In 2016 after two successful trips outside the curriculum, this open initiative was formally proposed and validated as a credit-bearing part of the curriculum. In order to transform the initial openinitiative into a module, there were benchmarks to address, learning outcomes to devise, appropriate assessments to formulate, and the module had to be appropriately situated within the degree programme. The BMus Music with Teaching degree prepares graduates to teach as self-employed practitioners; teaching instrumental/vocal lessons is part of the portfolio career of a performing musician. The approved module, MUS681 International Experience, occurs as the culmination of the four-year BMus degree and allows students to assimilate three years of theoretical learning and skills development through classroom-based peer-to-peer workshops. It transforms structured visits to local schools into a real-life setting where the students truly control, design, and implement the content of their teaching experiences.

The International Experience module aims for students to exercise personal agency and choice in developing different practical skills and exploring their application in a variety of teaching and performance contexts. Students are invited to apply to enrol on the International Experience module prior to their final year of study. The class is built on open learning, without a textbook, students connect beyond the walls of the classroom to create and curate resources and deliver their own content. Exercising student agency begins well before the class begins, with the responsibility of designing the details of their curriculum, and planning the details of their trip from travel logistics to the delivery and dates of their musical interactions throughout the module. The working environment created is one of co-learning, where students are engaged in the highest levels of autonomous learning.

Each cohort must self-organise in a way that attends to individual's needs, as well as connecting within and beyond the group to create an educational project. The students must also commit to planning and fundraising to support the outreach aspects of their teaching initiative: this experience is a valuable part of learning and sets the students up to truly take ownership of the curriculum. The modular content becomes the lived learning experience of the students' designed curriculum. This experiential learning enables self-efficacy beliefs to grow (see Zimmerman, 2000; Urdan \& Pajares, 2006; Ritchie, 2015) and as active self-directed learners, students engage with higher cognitive and self-regulation processes (Bembenutty, Cleary \& Kitsantas, 2013). The materials, processes, and delivery change with each cohort, and similarly the instructor's role also changes depending on the student goals.

The cross-cultural and collaborative interactions within the module, which are planned, but remain 'unknown' until the trip happens, highlight aspects of learning that Siemens (2005) describes as "nebulous environments of shifting core elements- not entirely under the control of the individual" (p. 5). Having to organise, navigate uncertainties, and each act as leaders for different aspects of the trip puts new responsibilities on students that impact learning differently to a closed classroom or textbook setting. The wider engagement with schools and communities well beyond the students' 
known home or study contexts contributes to developing student's perception and perspective. Throughout the module reflection is encouraged and stepping back, analysing, and documenting are elements of self-regulation and higher order cognitive skills that lead to meaningful comprehension, giving the students both knowledge and experience. The assessed reflective journal encourages students to detail their learning process and engage with deeper learning.

There is no template for the class and every cohort is different. For example, 2017 was the first credit-bearing year for the International Experience module and registered students included a pianist, a singer (who was blind), and a clarinettist; each had their own goals for the class. The pianist wanted to perform concerts in LA for a professional CV, the clarinettist wanted to be involved with the organisation of events and the logistical side of the trip, and the singer was interested in the physical learning settings in schools. The group worked together to accommodate each person's goals and create a curriculum that allowed each to excel, explore, and be pushed to the best of their abilities. "This was the time to take risks, and we did" (K. Rustage, speaking at RAISE Conference, 2017).

Students become both the learners and the leaders, and experience the transfer of skills from the classroom into potential future rolls as musicians and teachers. When the teacher becomes a co-learner, this creates a different dynamic; the teacher models learning, organisation, and performance for, but also with the students as they work together. The teacher does not lead or teach through directives. Another student explained the experience:

"Laura has that rare ability to teach people without actually teaching them. She opens doors so that they can learn for themselves. She doesn't actually tell you what to do." (S. Arthurs, speaking at RAISE Conference, 2017).

In this setting the teacher can facilitate and encourage, but needs the students to be able to complete the planned curriculum. We relied on one another and this made the whole experience of co-learning far more real. The people with whom we connected also became an integral part of the learning process. These open aspects of the class encourage both receptivity and inclusion. Each person plays a different role, and the assessed content of the module, allows individual reflection on both learning and process, helping to reinforce awareness and encourage deeper learning (Cowan, 2006; Gaunt, 2008).

The 2018 cohort was completely different, including a bassist, ukulele player, and singer, and their curriculum and experience, although focusing on the same skills of planning, communication, collaboration, inclusion, and performing, was also very different than past iterations. The group created a student-centred, individual and participatory experience for everyone. They delivered interactive workshops in Los Angeles primary schools, teaching ukulele and traditional Polish songs to children, and then adapting the workshops as training for UCLA students who volunteer as summer-camp staff for the UniCamp programme. The UCLA students will learn first to play and sing the songs, and then to teach them as workshops integrated within the curriculum of the summer camp programmes. This cohort raised funds to provide 60 instruments for UniCamp and schools they worked with in America.

\section{Outputs and impacts}

Each year, after the module, students have applied to and presented in conferences and given workshops on topics including engagement, collaboration, assessment, and creating networks. The sense that the value of the experience is not bounded by a timetabled slot, by expectations of learning 'things' or by assessment is important and prepares students for on-going learning and connection. Conference presentations and workshops to transfer skills developed to the realm of 
wider academic, performance, and teaching settings, giving these students experience in areas they could choose as future career paths.

The impact of that first student-led trip resulted in more than the adoption of open educational practice as a formal module. The original cohort and I realised the importance of communicating to our peers how ordinary students and teachers achieved beyond expectation, far from the walls around them and beyond textbooks. Often people only see the polished final product of learning in the form of a publication, performance, or presentation, and the challenges of negotiating learning processes are not made public. Both students and teachers have to figure this out on their own, and as with any learning, there needs to be self-belief to succeed. The strongest influence on self-efficacy is accomplishment, and the next most important influencer is vicarious experience (Bandura, 1997). Presenting the pedagogical practice from start to finish in the book, and including aspects of the individual and group journeys provided an outcome, a testimony to possibility, and continues to serve as model for future learners and educators.

The group documented their planning and learning processes and created an eBook: California Dreaming (Ritchie, 2017). The book was written collaboratively, integrating parts of blog posts, transcriptions of audio recordings, Slack conversations, and reflective contributions from international collaborators. For those involved in the original trip, demonstrating that ordinary university students and teachers could achieve something beyond expectation, far from the walls around them or the text in front of their eyes, was important to model for future learners and educators. The students wrote over 10,000 words of the text and it was not diluted or censored to show only the positive aspects, but includes the entire journey from the first Skype contact to California. In the spirit of openness the eBook was published with no DRM and is available to download for free.

\section{Applications across disciplines}

This initiative is transferable to other subject areas. Whether the concept is transferred to the context of a dissertation project or a module within a continuing curriculum, outcomes can be measured and thus including this type of 'open' within an institutional framework does not mean breaking from regulation, but aligning this new practice with existing and understood goals for deliverables. The module is underpinned by developing invaluable communication, time management, logistical, and leadership skills. Having these widely applicable skills at the centre of the validated document allows this module to act as a template for other disciplines, and the discipline-skills learned through a degree specialism can be addressed through the educational outreach aspect of the module. The specific tasks and content can be devised year on year as the curriculum is open.

The highly active involvement of individuals also suggests a small-group structure. It is possible that a scale adaption could be developed involving several groups of students being mentored by a teacher, yet acting independently. Teaching for personal learning, as opposed to using a fixed content curriculum or even content personalised for a group, is hugely rewarding for all involved. However, the teacher cannot completely control or foresee the direction of teaching and this goes against the traditional understanding that the teacher knows. It also requires humility and a real willingness to fail, because when mentoring and working together with students in the months before the trip as they create their curriculum of teaching, workshops, and site visits, the less-polished iterative stages of the project that are typically private will be seen and shared.

Students of any specialism can engage the wider public in both formal and informal contexts at settings such as schools, at libraries, and in community groups as they share an understanding and passion for their subject. Music does lend itself to public engagement, however the principle of this curriculum initiative can be directly applied to subjects far beyond this teaching-oriented class. 
For example, medical practitioners could create an engaging presentation and leave listeners with a model of the body, or a relevant artefact that could be used in further inspiring and educating those listening.

There are cost implications involving decisions about the extent to which such a class could be subsidised and whether students would be expected to also fund aspects of the trip. It is imperative that all participants are fully committed, as this ensures the success of the project. Including an outreach initiative and naming it helps students to own what they do and reinforces a purpose beyond credits or assessment. The outreach aspect becomes more valuable when sustained learning and wider connections with people's lives can be illustrated through the educational message. The concept behind the name Musiquality transcends any individual year group and allows for the uniqueness of successive cohorts while maintaining an underlying ethos. Ownership of the educational outreach also gives more impetus to include fundraising as part of the process, so students truly assume responsibility for all aspects of devising and carrying out their project. Students gain a sense of worth and accomplishment that comes with achieving iterative goals that prepare students for the practical learning that follows as they organise and implement the skills-specific aspects of their curriculum abroad.

\section{Conclusion}

Although initially opening the curriculum through this approach to teaching requires more effort from the teacher and significant commitment from the students, it is worth pursuing. It enables students to actively demonstrate agency and develop both subject-specific knowledge and a range of wider soft skills that enhance their employability (Knight \& Yorke, 2004). Engaging with a cross section people and cultures beyond typical learning circles expands perspectives, hones awareness of learning and communication, and helps to prepare students to live in a connected world.

\section{Acknowledgement}

This paper was presented at the 2018 Open Education Consortium Global Conference, held in Delft (The Netherlands) in April 24th-26th 2018 (https://conference.oeconsortium.org/2018), with whom Open Praxis established a partnership. After a pre-selection by the Conference Committee, the paper underwent the usual peer-review process in Open Praxis.

\section{References}

Askham, P. (2008). Context and identity: Exploring adult learners' experiences of higher education. Journal of Further and Higher Education, 32(1), 85-97.

Bandura, A. (1997). Self-efficacy: The exercise of control. New York: Freeman.

Bembenutty, H., Cleary, T. J. \& Kitsantas, A. (Eds.). (2013). Applications of self-regulated learning across diverse disciplines: A tribute to Barry J. Zimmerman. North Carolina: Information Age Publishing.

Blaschke, L. M. (2012). Heutagogy and lifelong learning: A review of heutagogical practice and self-determined learning. The International Review of Research in Open and Distributed Learning, 13(1), 56-71. http://dx.doi.org/10.19173/irrodl.v13i1.1076

Corneli, J., Dnaoff, C.J., Pierce, C., Ricaurte, P., \& Snow MacDonald, L. (Eds.) (2016). The Peeragogy Handbook ( $3^{\text {rd }}$ Ed.). Chicago: II/Somerville, MA: PubDomEd/Pierce Press. Retrieved from http:// Peeragogy.org

Cowan, J. (2006). On becoming an innovative university teacher: Reflection in action: Reflection in action. London: McGraw-Hill Education. 
De Freitas, S., Rebolledo-Mendez, G., Liarokapis, F., Magoulas, G., \& Poulovassilis, A. (2010). Learning as immersive experiences: Using the four-dimensional framework for designing and evaluating immersive learning experiences in a virtual world. British Journal of Educational Technology, 41(1), 69-85. https://doi.org/10.1111/j.1467-8535.2009.01024.x

Downes, S. (2017). Beyond institutions: Personal learning in a networked world. In S. Downes (Ed.). Toward personal learning. National Research Council Canada (pp. 347-375). Retrieved from http://www.downes.ca/files/books/Toward Personal Learning v09.pdf

Garrison, D. R., \& Vaughan, N. D. (2008). Blended learning in higher education: Framework, principles, and guidelines. San Francisco: Jossey-Bass.

Gaunt, H. (2008). One-to-one tuition in a conservatoire: The perceptions of instrumental and vocal teachers. Psychology of Music, 36(2), 215-45. https://doi.org/10.1177/0305735607080827

Horton, M., \& Freire, P. (1990). We make the road by walking: Conversations on education and social change. Philadelphia: Temple University Press.

Knight, P., \& Yorke, M. (2004). Learning, curriculum and employability in Higher Education. London: Routledge.

Kolb, D. A. (1984). Experiential learning: Experience as the source of learning and development (Vol. 1). Englewood Cliffs, NJ: Prentice-Hall.

Lehtomäki, E., Moate, J., \& Posti-Ahokas, H. (2015). Global connectedness in higher education: student voices on the value of cross-cultural learning dialogue. Studies in Higher Education, 41(11), 2011-2027. https://doi.org/10.1080/03075079.2015.1007943

Ritchie, L. (2015). Fostering Self-Efficacy in Higher Education Students. Palgrave Macmillan: London.

Ritchie, L. (2017). California dreaming. Effic Research Limited: London. Retrieved from https://www. lauraritchie.com/downloads/california-dreaming-pdf/

Rustage, K., Ritchie, L., Thomas, D., Arthurs, S. (2017). International experience: A co-created journey. Presentation in RAISE (Researching, Advancing, \& Inspiring Student Engagement) Conference, Manchester, UK.

Siemens, G. (2005). Connectivism: Learning as network-creation. ASTD Learning News, 10(1), 1-28. Retrieved from http://www.elearnspace.org/Articles/networks.htm

Urdan, T. \& Pajares, F. (2006). Self-efficacy beliefs of adolescents. Greenwich, Conn: IAP.

Zimmerman, B. (2000). Self-Efficacy: An Essential Motive to Learn. Contemporary Educational Psychology, 25(1), 82-91. https://doi.org/10.1006/ceps.1999.1016 